\title{
Study of Human Factors in Rural Kitchen Design
}

\author{
Promila Krishna Chahal ${ }^{1}$ and Manju Mehta² \\ ${ }^{1}$ Assistant Scientist, Department of Family Resource Management, COHS, CCSHAU, Hisar, Haryana, India \\ ${ }^{2}$ Professor and Head, Department of Family Resource Management, COHS, CCSHAU, Hisar, Haryana, India
}

*Corresponding author: promilakrishnachahal@hau.ac.in (ORCID ID: 0000-0001-8509-0137)

Received: 17-03-2021

Revised: 27-05-2021

Accepted: 10-06-2021

\begin{abstract}
The present study was undertaken to study the work, worker, and workplace interfacing in the selected standing type of kitchens in Behbalpur village of Hisar district. The study was conducted on 50 women respondents from the age group of $24-47$ years who were involved in kitchen activities for the last 2 years with at least 2 hrs daily. No separate counter was found for preparation, cooking, and washing activities. Only one work counter was found for all purposes with height and depth of $\bar{x}=94.2 \pm 4.44 \mathrm{~cm} \bar{x}=$ $61.8 \pm 7.8 \mathrm{~cm}$, respectively. It can be concluded that the height of the counter was not adequate and was either too high (20.0\%) or too low $(38.0 \%)$ in more than fifty percent of the kitchens. Regarding the depth of counter surface, the mean value of counter depth was $(\bar{x}=61.8 \pm 7.8 \mathrm{~cm})$ significantly higher than the usual horizontal reach of women $(\bar{x}=47.6 \pm 5.9 \mathrm{~cm})$. In all three groups, $\mathrm{p}$ values were less than 0.005 (5.82E-09, 2.3E-17, and 3.44E-10), representing the significant difference in means of each group, i.e., between counter height and standing elbow height, and between counter depth and horizontal reach(s).
\end{abstract}

\section{HIGHLIGHTS}

(0 Ergonomics mismatch between women's anthropometry and modular kitchen dimension in the rural Haryana.

Keywords: Counter height, horizontal reach (normal and extended), dimensions mismatch

The homemaker is the predominant figure in the home, and household work is an indispensable part of the homemaker. Kitchen work is considered the primary work area of women, and most of their time is spent doing kitchen work. A National survey shows that on average, an Indian woman spends approximately 3.2 hours a day in the kitchen for cooking and cleaning utensils (Johari, 2015). Kishtwaria et al. (2007) in their research, observed that Indian women spend on an average 5-6 hours in the kitchen, which may amount to approximately one-fourth of their life spans women spend $20-30 \%$ time in the kitchen, the work area and environment of the kitchen the kitchen's work area and environment play an important role in affecting the worker's health. The amount of time spent in the kitchen activity, the type of kitchen, the ergonomic benefits utilized by the homemakers in the kitchen are all critical factors to be considered for the well-being of the homemakers (Sultana and Prakash, 2013). The standing type of kitchen was popularized because of its various advantages, such as 'avoidance of frequent changes in posture' and 'smooth flow of work on a continuous work counter' (Thakur 2007). However, working in a standing type of kitchen has its own set of disadvantages for Indian women. This type of kitchen is more suitable

How to cite this article: Chahal, P.K. and Mehta, M. (2021). Study of Human Factors in Rural Kitchen Design. Int. J. Soc. Sci., 10(02): 99-107.

Source of Support: None; Conflict of Interest: None

(c) 9 
in western culture because it is less laborious and less time-consuming. Apart from prolonged standing, the poor design of the kitchen workplace also causes difficulties for the women. Studies have indicated that the work counters in the Indian kitchen are not designed according to anthropometric measurements of the women (Sandhu et al. 2007). There is another problem which generally women have reported in various studies is of difficulty in reaching out to too high shelves, which in standing type of kitchens are designed above the head clearance space. The height of the shelf force people to either raise their heels or use Patra/stool to reach the top shelf. Tiptoeing to reach out topmost shelves also increases human costs (Kumari and Dayal, 2009).

Poorly designed kitchen work surfaces and spaces cause' permanent body damage besides increasing the worker's workload. A significant number of studies have indicated that women consider kitchen or household work as a significant domestic drudgery, a threat to well-being, and a hindrance in overall work satisfaction (Haukka et al. 2008). The primary reason for increased physiological stresses while working in a standing type of kitchen is prolonged standing at a stretch and no place to sit, which can relieve their stress while working for a longer duration and mismatch between women anthropometry and kitchen counter dimensions. Adequately designed and properly arranged kitchen work area reduces the physical, physiological and temporal cost of homemakers. Ergonomically designed counter saves time and reduces effort by eliminating unnecessary actions that need to be taken to get the job done. This study aimed to demonstrate the relationship and mismatch between the dimensions of the cooking counter and the anthropometry of women working inside a kitchen in a rural area.

\section{METHODOLOGY}

The present study was conducted in Behbalpur village of Hisar district. 50 women respondents, who were actively working in the kitchen for the last 2 years and at least $2 \mathrm{hrs}$ daily, were taken as respondents. The existing condition of women in the kitchen was checked, including socioeconomic profile, kitchen type, kitchen size, counters available, specific height and measurements of the kitchen counter/shelves, and involvement pattern of women in the kitchen. Anthropometric measurements of women who were found to be working in the kitchen were taken, including; age, weight, standing height, standing elbow height, average horizontal reach, and extended horizontal reach. Dimensions of the kitchen, height, and depth of cooking counter were taken during the study by using an inch tape. In the study, a single counter was found to be used by women for all purposes like; preparation, cooking and washing utensils. Counter height and depth were recorded and studied in correlation with standing elbow height and regular and extended horizontal reach. During the study, different abbreviations were used for different terms (Table 1).

The degree of difference between anthropometric measurements and dimensions of the kitchen were studied in 3 groups which were as follow:

* Group 1 = Relation between standing elbow height $(\mathrm{cm})$ and counter height $(\mathrm{cm})$.

* Group 2 = Relation between Normal horizontal reach $(\mathrm{cm})$ and counter depth $(\mathrm{cm})$.

* Group 3 = Relation between extended horizontal reach $(\mathrm{cm})$ and counter depth $(\mathrm{cm})$.

\section{ANALYSIS OF DATA}

For significant means of data, statistical analysis was done. Anthropometric measurements and dimensions of the kitchen were statistically studied by using mean, standard deviation, $10^{\text {th }}$ percentile, $50^{\text {th }}$ percentile, and $95^{\text {th }}$ percentile. ANOVA was used to test the significant relation and difference between two means of groups (13). One-way analysis of variance was used to determine the factors of those mean were statistically significant or not (Snedecor and Cochran, 1989).

\section{RESULTS AND DISCUSSION}

The study was conducted on 50 women respondents from the age group of 24-47 years who were involved in kitchen activities for the last 2 years with at least 2 hrs daily. The majority of the houses $(78.0 \%)$ had Peninsula/ G type of kitchen, and most of these (52.0\%) were 5-12 years old. More than fifty percent of women 
Table 1: Abbreviation and definition of terms used in study

\begin{tabular}{|c|c|c|}
\hline Terms & Abbreviation & Definition \\
\hline Standing Height & $\mathrm{SH}$ & $\begin{array}{l}\text { Human height or stature is the distance from the bottom of the feet to the top of } \\
\text { the head in a human body, standing erect. It is measured using a stadiometer, } \\
\text { usually in centimeters when using the metric system, or feet and inches when } \\
\text { using the imperial system }\end{array}$ \\
\hline Standing Elbow Height & SHE & $\begin{array}{l}\text { The vertical distance from the floor to the radiale. (The rediale is the bony } \\
\text { landmark formed by the upper end of the radius bone which is palpable on the } \\
\text { outer surface of the elbow.) Applications: An important reference datum for the } \\
\text { determination of work-surface heights }\end{array}$ \\
\hline Normal Horizontal Reach & NHR & $\begin{array}{l}\text { This is the reach created by the vertical sweep of the forearm while keeping the } \\
\text { elbow at a mid-torso level. }\end{array}$ \\
\hline Extended Horizontal Reach & HER & $\begin{array}{l}\text { Extended vertical reach. This is the reach created when the upper arm is fully } \\
\text { extended }\end{array}$ \\
\hline Counter Height & $\mathrm{CH}$ & "Counter Height " is the Vertical distance from the floor to the top of the counter \\
\hline
\end{tabular}

(54.0\% and $52.0 \%$ ) were found to be involved in the morning (breakfast) and night (dinner) time kitchen activities for 2:00-2:30 hrs daily, and 58.0 percent women were involved in kitchen work for 30 minutes besides breakfast, lunch, and dinner. No separate counter was found for preparation, cooking, and washing activities; only one work counter was found for all purposes with height and depth of $\bar{x}=94.2 \pm 4.44 \mathrm{~cm} \times \bar{x}=61.8 \pm 7.8 \mathrm{~cm}$, respectively. Regarding counter availability and use of kitchen, cent percent kitchen was having facilities of preparation, cooking and storage counter and was in used by women in standing posture. However, the dishwashing (sink) facility was found only in 22.0 percent of the kitchen. It was not used for cleaning purposes as they washed the utensil outside the kitchen in a squatting posture. Khatoon et al. (2007) in their study on dish-washing activity, also reported that the majority of the respondents adopted a bending posture for bringing utensils from the kitchen to the cleaning area and 70 percent of respondents adopted sitting cum bending posture for scrubbing the utensils. The data represent women's anthropometric measurements, including age, weight, stature, standing elbow height, and women's anthropometric measurements, including age, weight, stature, standing elbow height, and horizontal reach (normal and maximum). All the measurements were measured in means and percentile values $\left(10^{\text {th }}, 50^{\text {th }}\right.$, and $\left.95^{\text {th }}\right)$. The women's standing height (stature) was /=160.25 $\pm 5.30 \mathrm{~cm}$ with /=152.64 cm, /=159.55 am, and $/=167.6 \mathrm{~cm}$ height of $10^{\text {th }}, 50^{\text {th }}$, and $90^{\text {th }}$ percentiles respectively. Regarding the standing shoulder height of the women', data reflect that the mean shoulder height was $95.67 \mathrm{~cm}$ with $10^{\text {th }}, 50^{\text {th }}$ and $95^{\text {th }}$ percentile of $91.3 \mathrm{~cm}$, $95.2 \mathrm{~cm}$, and $100.7 \mathrm{~cm}$, respectively. The standing elbow height of women was reported to be $99.50 \pm 3.52 \mathrm{~cm}$ with three percentile values of $94.45 \mathrm{~cm}, 99.04 \mathrm{~cm}$, and 104.38 $\mathrm{cm}$ on $10^{\text {th }}, 50^{\text {th }}$ and $90^{\text {th }}$ percentile values. Horizontal reach at a normal and maximum point was $\bar{x}=47.64 \pm$ $5.98 \mathrm{~cm}$ and $\bar{x}=72.77 \pm 7.48 \mathrm{~cm}$, respectively. Findings unveil the measurements of the cooking counter. Only one counter was found for all purposes of cooking and preparation. In some houses washing area was found to be outside of the kitchen and a few houses had a sink counter in the kitchen but it was rarely used for washing utensils. The mean height of the counter was found to be $\bar{x}=94.27 \pm 4.44 \mathrm{~cm}$ and depth was $\bar{x}=62.05 \pm 8.13 \mathrm{~cm}$.

\section{Dimensions mismatch between counter height and standing elbow height of women}

Results in Table 2 explain the dimensions mismatch between the cooking counter height of the kitchen and the standing elbow height of women. The difference between standing elbow height and counter height was observed by calculating the degree of difference 
Table 2: Dimensions mismatch between counter height and standing elbow height of women




between both. Data in the table give a clear glance that each woman's measurement (standing elbow height) was statistically checked with the dimension of their kitchen's cooking counter height to find out the correlation and mismatch between them. Regarding the result, 38.0 percent of women' kitchen counter heights were less than their standing elbow height, followed by 42.0 percent kitchens' counter were found to be appropriate for use as their dimension was found significantly correlated with each other (at \pm of $5 \mathrm{~cm}$ ) and 20.0 percent women' kitchen counter height was noticed to be high then their standing elbow height, the height difference was found to be more than $5 \mathrm{~cm}$. The overall mean values of standing elbow height and counter height were $\bar{x}=99.5 \pm 3.4$ and $\bar{x}=94.2 \pm 4.4$, respectively. It can be concluded that the height of the counter was not adequate and was too high (20.0\%) and too low $(38.0 \%)$ in more than fifty percent of the kitchens. A study done by Charu (2014) revealed that an average height of the cooking, preparation center, and sink were observed to be $\bar{x}=85.30 \mathrm{~cm}, \bar{x}=85.73 \mathrm{~cm}$, and $\bar{x}=85.85 \mathrm{~cm}$, respectively which were not according to the anthropometric measurement of the respondents. Approximately 20.0 percent have to raise their heels to reach and use the counter and sometimes have to use patra. Suppose the user in a kitchen is working on a worktop that is too low or too high. In that case, it causes that person to stand in a wrong way for a prolonged time, causing all sorts of problems such as back pains, neck pains, and various spasms throughout the body, making them very uncomfortable (Tehrani, 2012). Cooking counter height was found to be significantly $(t=0.14)$ different (less and more than elbow height) of women' elbow height).

\section{Dimensions mismatch between counter depth and horizontal reach(s) of women}

Data in table 3 revealed the dimensions mismatch between counter depth of kitchen with horizontal reach (standard and extended) of respective women from each kitchen (normal and extended). Two horizontal

Table 3: Dimensions mismatch between counter depth and horizontal reach(s) of women

\begin{tabular}{|c|c|c|c|c|c|c|}
\hline Sl. No. & $\mathrm{CD}$ & NHR & Difference & CD & EHR & Difference \\
\hline 3 & 71.1 & 50.8 & $20.3 \uparrow$ & 71.1 & 68.5 & $2.5 \leftrightarrow$ \\
\hline 5 & 66.0 & 48.2 & $17.7 \uparrow$ & 66.1 & 67.3 & $-1.2 \downarrow$ \\
\hline 6 & 55.8 & 56.6 & $-0.7 \downarrow$ & 55.8 & 82.5 & $-26.6 \downarrow$ \\
\hline 7 & 50.8 & 45.7 & $5.1 \leftrightarrow$ & 50.8 & 66.1 & $-15.2 \downarrow$ \\
\hline 10 & 59.6 & 57.1 & $2.5 \leftrightarrow$ & 59.6 & 83.8 & $-24.1 \downarrow$ \\
\hline 11 & 45.7 & 53.3 & $-7.6 \downarrow$ & 45.7 & 76.2 & $-30.4 \downarrow$ \\
\hline 12 & 50.8 & 52.7 & $-1.2 \downarrow$ & 50.8 & 72.3 & $-21.5 \downarrow$ \\
\hline 13 & 57.1 & 54.6 & $2.5 \leftrightarrow$ & 57.1 & 81.5 & $-24.3 \downarrow$ \\
\hline 14 & 66.4 & 59.6 & $6.3 \uparrow$ & 66.1 & 82.5 & $-16.5 \downarrow$ \\
\hline 19 & 62.2 & 62.2 & $0.1 \leftrightarrow$ & 62.2 & 92.7 & $-30.4 \downarrow$ \\
\hline 20 & 58.4 & 46.9 & $11.4 \uparrow$ & 58.4 & 69.8 & $-11.4 \downarrow$ \\
\hline 21 & 71.1 & 40.6 & $30.4 \uparrow$ & 71.1 & 62.2 & $8.8 \uparrow$ \\
\hline 22 & 65.2 & 48.2 & $16.7 \uparrow$ & 65.1 & 73.4 & $-8.3 \downarrow$ \\
\hline 23 & 62.9 & 43.1 & $19.8 \uparrow$ & 62.9 & 64.7 & $-1.7 \downarrow$ \\
\hline
\end{tabular}




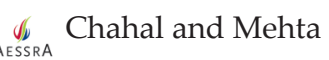

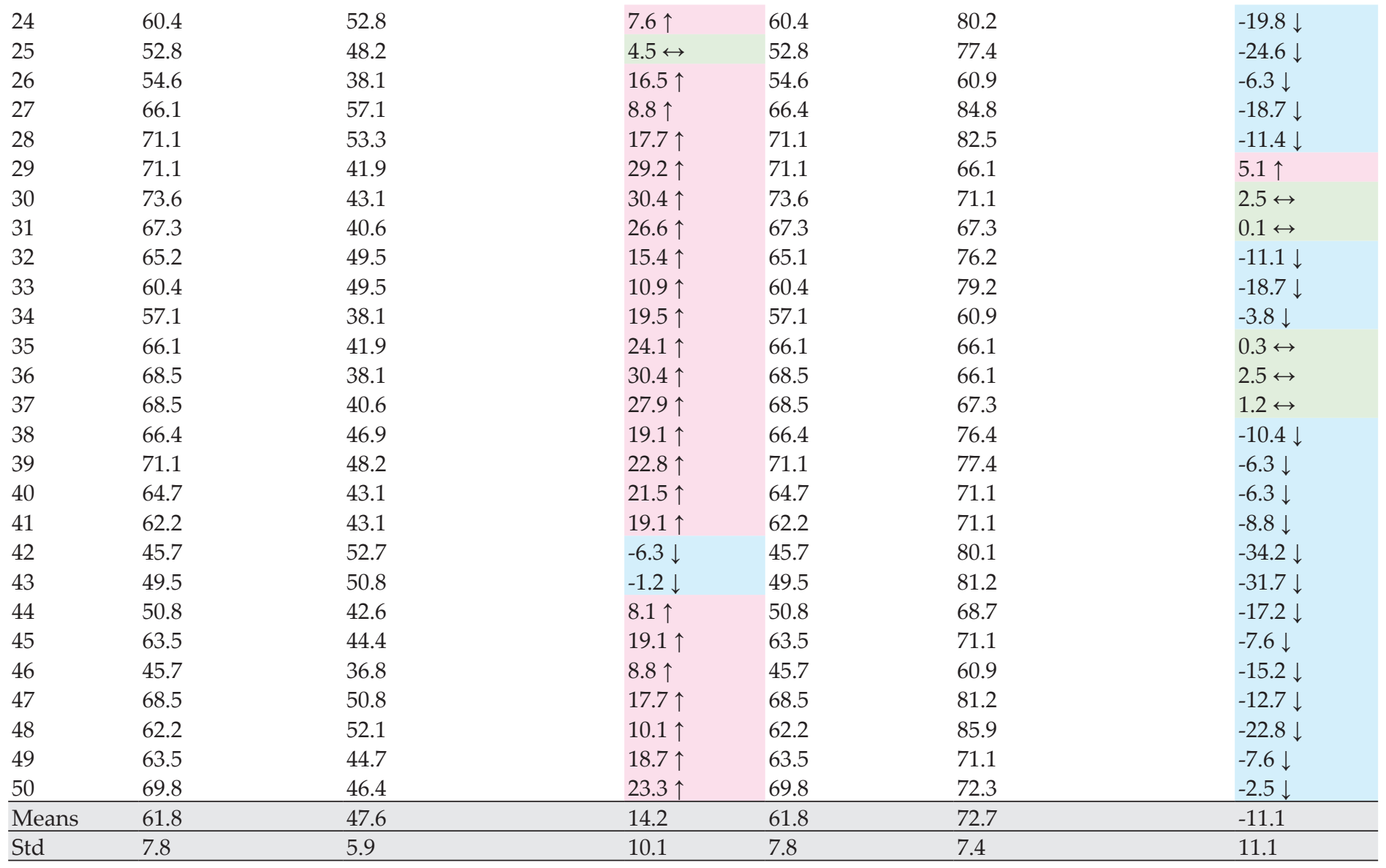

(CD less than HR by the sign of $\downarrow$ and use of blue color), CD correlated with HR (by the sign of $\leftrightarrow$ and use of green color) and CD more than HR (by the sign of $\uparrow$ and use of green color).

Counter-depth $\pm 5 \mathrm{~cm}$ to horizontal was considered as appropriatel well suited to women.

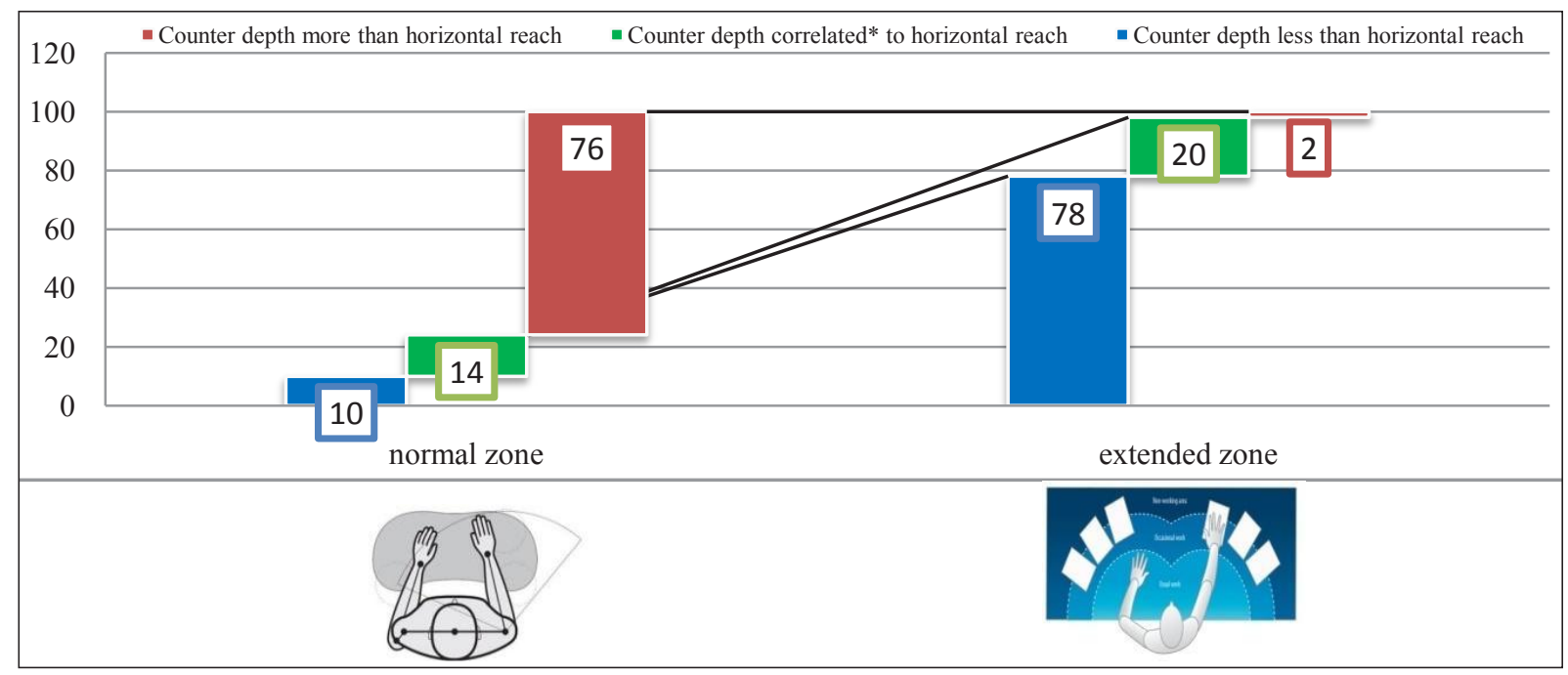

Fig. 1: Dimensions mismatch between counter depth and horizontal reach(s) of women 
reaches were recorded as (by keeping elbow near to body) and extended (stretching full elbow). Each woman's horizontal reach(s) was studied with their counter depth, and results were found out based on the correlation between these components. Regarding the depth of counter surface, the mean value of counter depth was $\bar{x}=61.8 \pm 7.8 \mathrm{~cm}$ which was found to be significantly high than the usual horizontal reach of women $(\bar{x}=47.6 \pm 5.9 \mathrm{~cm})$ another side it was under the extended horizontal reach of women $(\bar{x}=72.7 \pm 7.4 \mathrm{~cm})$. Regarding the normal zone of women (within average reach), full kitchens' counters $(76.0 \%)$ were having more counter depth comparative to the standard horizontal reach of women, followed by 14 percent kitchen counters' depth were significantly matched (at $\pm 5 \mathrm{~cm}$ ) with an average horizontal reach of women. Only 10 percent kitchen counter depth was found to be less than women's horizontal reach. Finding further gives a clear picture of the dimension mismatched between counter depth and extended horizontal reach of women. As per findings in Table 3 and Fig. 1, show the majority of the kitchens' counter depth $(78.0 \%)$ were found to be less than the extended horizontal reach of women, followed by 20.0 percent kitchens' counter depth were found to be significantly correlated (at $\pm 5 \mathrm{~cm}$ ) with an extended horizontal reach of women. Only 2.0 percent kitchen counter depth were observed to be more than extended horizontal reach means women were not found to be able to use these counter with comfort. Similar findings were found by Kishtwaria et al. (2007) that dimensions (height $\times$ width $\times$ depth) of cooking and preparation centers were $\bar{x}=85.29 \pm 4.01 \mathrm{~cm} \bar{x}=105.78 \pm 20.34 \mathrm{~cm} \bar{x}$ $=59.9 \pm 5.0 \mathrm{~cm}$ and $\bar{x}=85.73 \pm 2.78 \mathrm{~cm} \bar{x}=117.35 \pm 37.80 \mathrm{~cm}$ $\bar{x}=59.96 \pm 4.86 \mathrm{~cm}$, respectively, which were not found to be associated with an anthropometric dimension of women. Poorly designed work surfaces in terms of counter height, width, and depth cause permanent body damage besides increasing the work; hence it should be carefully scrutinized.

\section{Relation between anthropometric measurements of women and dimensions of cooking counter}

Results in Table 4 define the relation between anthropometric measurements of women and the dimension of counters in the kitchen. Report of result on one-way ANOVA give a clear picture of findings as means, Minimum value, Maximum value, $10^{\text {th }}$ percentile, $50^{\text {th }}$ percentile, 95 percentile, $\mathrm{F}$ crit, $\mathrm{F}$ value, and $\mathrm{P}$-value. As per ANOVA (analysis of variance) if the $F$ value is less than the $\mathrm{F}$ crit, then the means of both groups are the same or significantly correlated. Otherwise, the means significantly different from the p-value. In all the groups, $\mathrm{p}$ values were found to be less than 0.005 (5.82E-09, 2.3E-17 and 3.44E-10,) which represent that it is significantly different in means of each group (reflect that kitchen counters' dimensions were not equal or

Table 4: Relation between anthropometric measurements of women and dimensions of cooking counter

\begin{tabular}{|c|c|c|c|c|c|c|}
\hline & \multicolumn{2}{|c|}{ Group 1} & \multicolumn{2}{|c|}{ Group 2} & \multicolumn{2}{|c|}{ Group 3} \\
\hline & SEH & $\mathrm{CH}$ & NHR & CD & EHR & CD \\
\hline Mean & $99.5 \pm .4$ & $94.2 \pm 4.4$ & $47.6 \pm 5.9$ & $61.8 \pm 7.8$ & $72.7 \pm 7.4$ & $61.8 \pm 7.8$ \\
\hline Maximum value & 106.3 & 102.8 & 62.2 & 73.6 & 92.7 & 73.6 \\
\hline $10^{\text {th }}$ percentile & 94.4 & 89.1 & 40.6 & 50.8 & 64.7 & 50.8 \\
\hline Fcrit & 3.94 & & 3.94 & & 3.94 & \\
\hline F value & 40.89 & & 107.7 & & 49.02 & \\
\hline$P$ value & $5.82 \mathrm{E}-09$ & & 2.3E-17 & & $3.44 \mathrm{E}-10$ & \\
\hline
\end{tabular}

Group $1=$ Relation between standing elbow height $(\mathrm{cm})$ and counter height (cm); Group 2 = Relation between Normal horizontal reach (cm) and counter depth (cm); Group 3 = Relation between extended horizontal reach $(\mathrm{cm})$ and counter depth $(\mathrm{cm})$; Significant at p-value of 0.05; Degree of freedom = 96. 
matched with measurements of women). The same findings were reflected in data that $\mathrm{F}$ values were high $(40.89,107.7$, and 49.02) than F crit (3.94), which reflected a significant difference in means of each group.

\section{Summary}

It can be concluded that the height of the counter was not adequate and was either too high $(20.0 \%)$ or too low $(38.0 \%)$ in more than fifty percent of the kitchens. The working counter was found to be at the same height for all activities like; preparation and cooking and sometimes cleaning. No separate counter and particular height and width were observed as per the requirements of women. "The height of the kitchen work counter, the proper clearance between cabinets or appliances for circulation, the accessibility to an overhead or undercounter storage, and proper visibility, are among the primary consideration in the design of cooking spaces. (Tehrani, 2012). Women were found to be using stool or Patra to reach and grasp the material, which sometimes also causes injuries and falls. It has also been found by Sandhu et al. (2008) in their study on the availability of kitchen workspaces and their suitability in the houses, that many users from all height categories felt 'stress in shoulder and arms' while using the highest dish stacking and kitchen storage shelf. They also felt 'stress in the leg' due to more cooking and kneading center coupled with prolonged standing. Rural villages are adopting the advanced technologies of cities, but sometimes they missed the concept behind that. The same was found in standing kitchen design, rural people were found to be using modern kitchen, but they were not found to involved the ergonomics of kitchen design. No one kitchen was found appropriate/fit to users (women) working 5-6 hrs daily inside the kitchen. The process of kitchen work and the activities contained within the kitchen, reflect the requirements that need to be considered to design smart kitchens with components suitable for that particular house such as storage, preparation/cooking, dining, and accessibility of the cabinets being the most critical requirements (Young Jun Ko, 2007). In all the groups, $p$ values were found to be less than 0.005 (5.82E-09, 2.3E-17, 3.44E-10,) which represents that there is a significant difference in means of each group (reflect that kitchen counters' dimensions were not equal or matched with measurements of women). Working in the kitchen puts much stress on women, especially if conducted in awkward postures and a poor work environment. The major causes of poor work practices were unconsciousness, unawareness, and poor storage and work counter infrastructure. (Laddha and Shraddha, 2007). As per the study findings, it seems that many rural kitchens were not ergonomically sound. This suggests that there is a need to create awareness among kitchen users regarding the functional requirements of the kitchen (Debata, B. 2011). If not designed according to ergonomic principles, the workplace can lead to various difficulties and workrelated musculoskeletal pain.

\section{REFERENCES}

Charu, 2014. Developing ergonomically designed kitchen aid for reducing physiological stress of women working in standing type kitchen, Thesis Ph.d (Family Resource Management). College of Home Science Punjab Agricultural University, Ludhiana

Haukka, E., Leino-Arjas, P., Vikari-Juntura, E., Takala, E.P., Malmivaara, A., Hopsu, L., Mutanen, P., Krtola, R, Virtanen, T, Pehkonen, M.I., Holtaru-Leino, M., Nykanen, J., Stenholm, S., Nykri, E. and Rihimaki, H. 2008. A randomized controlled trial on whether a participatory ergonomics intervention could prevent musculoskeletal disorders. Occup. Environ. Med., 65: 849-856.

Johari, A. 2015. Will a government study confirm what we always knew: Indian women work more hours than men. Gender inequality. https://scroll.in/article/702430/will-a-governmentstudy-confirm-what-we-always-knew-indian-women-work-morehours-than-men. Last accessed on $16^{\text {th }}$ December 2020.

Khatoon, J., Verma, B. and Dayal, R. 2007. Grip assessment of rural women performing dishwashing activity in Deoria district (U.P.) 2: 125-131. In: Gite, L.P., Mehta, C.R., Kotwaliwale, N. and Majumdar, J. (ed) Developments in Agricultural and Industrial Ergonomics. Allied Publishers Pvt. Ltd, New Delhi.

Kishtwaria, J., Mathur, P. and Rana, A. 2007. Ergonomic evaluation of kitchen work concerning space designing. J. Hum. Ecol., 21: 43-46.

Kumari, P. and Dayal, R. 2009. Feeling of discomfort perceived by rural women while working in the existing kitchen arrangements. Asian. J. Home Sci., 3(2): 158-160.

Laddha, S. and Shraddha, 2007. Impact of work practices on musculoskeletal problems of rural women. Proc Humanizing Work and Work Environment (HWWE). Pp 67. Central Institute of Agricultural Engineering, Bhopal, India. 
Sandhu, P., Malik, M. and Bakhshi, R. 2008. Recommendations for selected household workstations for Punjabi (Indian) women. Proc. $9^{\text {th }}$ Southeast Asian Ergon. Conf. (SEAES). pp 60. Bangkok, Thailand.

Sandhu, P., Malik, M. and Kaur, H. 2007. Analysis of gap between existing and formulated kitchen work counters in selected households of Ludhiana city. J. Dairying, Foods and Home Sci., 26(1): 42-47.

Snedecor, George, W., Cochran, and William, G. 1989. Statistical Methods, Eighth Edition, Iowa State University Press.

Sultana, S. and Prakash, C. 2013. Benefits of using ergonomic kitchen designs for today's homemaker. Golden Research Thought, 3(6): 1-7.
Tehrani, M.M. 2012. The Role of Technology in Providing the Efficiency of Kitchen Design. Master of Science in Architecture. Eastern Mediterranean University Gazimağusa, North Cyprus.

Thakur, V. 2007. Modular smart kitchen workstation. Master of Design Thesis, Indian Institute of Technology, Kanpur, India.

Verghese, M.A., Chattarjee, L., Aterya, N. and Bhatnagar, A. 1989. Ergonomic Evaluation of Household Activities UGC Report. Dept of Family Resource Management, SNDT, Bombay, India.

Young Jun Ko, H.R. 2007. Expanded Evaluation System for Design. 
